\title{
Assessment of Botryosphaeria stevensii detection by DNA barcoding
}

\author{
Wang $Y^{1,2,3}$, Gao $\mathrm{RF}^{1,2,3}$, Zhang GM${ }^{1,2,3 *}$, Cheng $\mathrm{YH}^{1,2,3}$, Shi $\mathrm{YQ}^{1,2,3}$, Li FR ${ }^{1,2,3}$, \\ Pan $\mathbf{G}^{1,2,3}$, Xiang $C Y^{1,2,3}$
}

\footnotetext{
${ }^{1}$ Shenzhen Entry-exit Inspection and Quarantine Bureau, Shenzen, 518045 Guangdong, P.R. China

${ }^{2}$ State Key Quarantine Laboratory of Legume Pest \& Plant Pathogenic Fungi of AQSIQ, Shenzhen, 518045 Guangdong, P.R. China

${ }^{3}$ Shenzhen Key Laboratory of Inspection Research \& Development of Alien Pests, Shenzhen, 518045 Guangdong, P.R. China
}

Wang Y, Gao RF, Zhang GM, Cheng YH, Shi YQ, Li FR, Pan G, Xiang CY 2019 - Assessment of Botryosphaeria stevensii detection by DNA barcoding. Plant Pathology \& Quarantine 9(1), 52-63, Doi 10.5943/ppq/9/1/6

\begin{abstract}
Botryosphaeria stevensii is a fungus that infects several tree species and causes cankers. In this study, 139 strains of 12 species in the genus Botryosphaeria isolated from infected apple trees were selected for assessing feasibility of identifying Botryosphaeria stevensii using DNA barcoding method with three potential marker genes: translation elongation factor 1alpha $(E F-1 \alpha)$, the internal transcribed spacer (ITS) and $\beta$-tubulin. By means of intraspecific and interspecific interval and cluster analysis and Wilcoxon rank sum testing, the ranking of the three tested genes for distinguishing intraspecific and interspecific genetic distance in B. stevensii is as follows: $E F$ $1 \alpha>\beta$-tubulin $>$ ITS. DNA barcoding using the three tested genes was shown to be suitable for detection of three Botryosphaeria stevensii strains isolated from the United States and New Zealand. Therefore, DNA barcoding based on the sequence of the EF-1 $\alpha$ gene could be used to rapidly identify B. stevensii infecting apple trees.
\end{abstract}

Key words - apple trees - Botryosphaeria stevensii - fungus identification

\section{Introduction}

Botryosphaeria stevensii Shoemaker (anamorph Diplodia mutila (Fr.) Mont.), a fungus found in the United States, Canada, Australia and 20 other countries, is quarantined as a harmful organism once detected on infected plants at the entry to China and Mexico. B. stevensii can infect 18 genera of important economic crops, including Malus, Pyrus, and Vitis. Infections can affect the stem, leaf, and fruit, giving rise to symptoms such as cankers, cancerous swelling, necrosis of the stem, yellow, withered leaves, and fruit rot, causing huge economic losses (Farr \& Rossman 2018, Wang et al. 2014, http://www.indexfungorum.org/Names/Names.asp).

In 2002 in a vineyard in New South Wales, Australia, cankers caused by two fungi, $B$. stevensii and B. obtusa, resulted in approximately $97 \%$ reduction in production of grape plants and led to nearly total crop failure (Whitelaw-Weckert et al. 2006). In the early 2000s, the value of the annual grape industry output of the state of California in the United States was 2.3 billion dollars,

Submitted 24 May 2018, Accepted 7 October 2018, Published 12 March 2019

Corresponding Author: Zhang G.M. - e-mail-zgm2001cn@163.com 
with more than 260 million dollars of losses caused by stem canker per year (Urbeztorres et al. 2006).

The genus Botryosphaeria contains 247 species, of which 12 can infect apple trees. Identification of Botryosphaeria species is difficult and time consuming because of their small interspecific differences and the difficulty of inducing sporulation in vitro. With rapid progress in molecular biology in recent years, species that were difficult to identify by traditional morphological and biological methods can now be identified by molecular methods. However, so far there are no reports on rapid identification of B. stevensii. DNA barcoding is a rapid and accurate molecular diagnostic technique by which species are identified using a standard DNA sequence (Hebert et al. 2003, Miller 2007). In this study, the EF-1 $\alpha$, ITS and $\beta$-tubulin genes from 12 species of Botryosphaeria that damage apple trees were tested to assess their suitability for DNA barcoding to rapidly identify pathogenic fungi in the genus Botryosphaeria. The suitability of the selected DNA barcoding sequences was verified using B. stevensii isolates from apples imported from North America and New Zealand.

\section{Materials \& Methods}

\section{DNA sequences for DNA barcoding screening}

First, 10270 sequences of the $E F-1 \alpha$, ITS and $\beta$-tubulin genes from 12 pathogenic Botryosphaeria species that infect Malus pumila (apple) were downloaded from the GenBank database (download date was 30 December 2016). Using Mega 5.0 software for alignment to arrange the three genes, each sequence was proof-read and verified to eliminate low quality sequences, sequences for which the number of uncertain base pairs exceeded $10 \mathrm{bp}$, and sequences shorter than $100 \mathrm{bp}$, after which reverse complementation and adjustment of sequence direction was performed. The representative strains and sequences of each pathogenic fungus were identified and shown in Table 1 (400 sequences from 139 strains).

Table 1 Sequence information for EF-1 $\alpha$, ITS and $\beta$-tubulin in 12 Botryosphaeria species that infect Malus pumila.

\begin{tabular}{lllll}
\hline \multirow{2}{*}{ Species } & \multirow{2}{*}{ Strain number } & \multicolumn{3}{c}{ GenBank number } \\
\cline { 3 - 5 } Botryosphaeria & CBS 122026 & KX4646 & ITS & 林bulin \\
& CBS 114823 & KX464671 & KX464161 & KX464950 \\
& UCR1110 & JF271793 & JF271758 & KX464947 \\
& CMW6853 & AY339271 & AY339263 & JF271776 \\
& CMW3386 & AY615157 & AY615165 & AY615149 \\
Botryosphaeria & CBS 119046 & EU017541 & DQ299244 & KU198429 \\
dothidea & MUCC503 & EF591970 & EF591918 & EF591953 \\
& UCD2432TX & GU294714 & FJ790844 & GU294728 \\
& SXD1221 & KC961072 & KC960982 & KF005078 \\
& LJL5521 & KC961069 & KC960978 & KC961024 \\
& JCC1311 & KC961043 & KC960918 & KC960996 \\
& BD140 & JQ900341 & JN545840 & JQ900375 \\
& Mht-19 & KC864748 & KC864746 & KC864747 \\
& N14 & KM349761 & KJ863654 & KJ863647 \\
& PD296 & GU251236 & GU251104 & GU251764 \\
& PD315 & GU251235 & GU251103 & GU251763 \\
& PD313 & GU251233 & GU251101 & GU251761 \\
& SNN5711 & KC961065 & KC960973 & KF005077 \\
& EN22931 & KC961059 & KC960957 & KC961015 \\
& LJF2121 & KF005081 & KC960933 & KC960998 \\
& ZY-713 & HQ660488 & HQ660462 & HQ660465 \\
& UF0730 & GQ869643 & GU595170 & JN607154 \\
\hline
\end{tabular}


Table 1 Continued.

\begin{tabular}{|c|c|c|c|c|}
\hline \multirow{2}{*}{ Species } & \multirow{2}{*}{ Strain number } & \multicolumn{3}{|c|}{ GenBank number } \\
\hline & & $E F-1 \alpha$ & ITS & $\beta$-tubulin \\
\hline & $\mathrm{zz}-1-3-1 \mathrm{~s}$ & JX462307 & JX275785 & JX462281 \\
\hline & J531 & КС961039 & KC960907 & KC960993 \\
\hline & SDAU07161 & FJ265873 & FJ171721 & FJ238530 \\
\hline & SENC65 & JN607109 & JN607086 & JN607132 \\
\hline & GS-02s-6 & JF441076 & JF441086 & JF441080 \\
\hline & EW23111 & КC961061 & КС960959 & KC961017 \\
\hline & YZN1311 & КС961040 & КС960910 & KC960994 \\
\hline & HuB10s1 & JX462294 & JX275786 & JX462268 \\
\hline & HeNs1 & JX462292 & JX275784 & JX462266 \\
\hline & LPSU2012127 & KX091156 & KX091152 & KX091155 \\
\hline & CMW8000 & AY236898 & AY236949 & AY236927 \\
\hline & CMW3910 & HM176507 & HM176522 & HM176485 \\
\hline & CMW3903 & HM176506 & HM176521 & HM176484 \\
\hline & MUCC501 & EF591969 & EF591916 & EF591952 \\
\hline & MUCC500 & EF591968 & EF591915 & EF591951 \\
\hline \multirow{4}{*}{$\begin{array}{l}\text { Botryosphaeria } \\
\text { iberica }\end{array}$} & CBS 113188 & EU673278 & AY573198 & N/A \\
\hline & UCD1448SLO & EF202023 & EF202009 & EF202016 \\
\hline & PD257 & GU251300 & GU251168 & GU251828 \\
\hline & CBS 115041 & AY573222 & NR_111165 & N/A \\
\hline \multirow{9}{*}{$\begin{array}{l}\text { Botryosphaeria } \\
\text { lutea }\end{array}$} & CBS 764.73 & KX464692 & KX'- 64970 & KX464970 \\
\hline & CMW9076 & AY339265 & AY236946 & AY339249 \\
\hline & CBS 110299 & AY573217 & AY259091 & DQ458848 \\
\hline & CMW10310 & AY339267 & AY339259 & AY339251 \\
\hline & UCR1180 & JF271798 & JF271798 & JF271782 \\
\hline & UCR1192 & N/A & JF921874 & JF921874 \\
\hline & UCD369-Oe & JX515765 & JX515719 & JX515687 \\
\hline & UCR548 & N/A & HQ529761 & HQ529731 \\
\hline & CMW10309 & AY339266 & KF766202 & AY339250 \\
\hline \multirow{13}{*}{$\begin{array}{l}\text { Botryosphaeria } \\
\text { obtusa }\end{array}$} & UCR1653 & JQ659270 & JQ659282 & JQ659294 \\
\hline & CBS 119049 & DQ458874 & DQ458889 & DQ458857 \\
\hline & CBS 469.69 & KX464611 & KX464119 & KX464847 \\
\hline & SDZ-01 & HQ629958 & HQ629954 & HQ629956 \\
\hline & CBS 358.68 & KX464610 & KX464118 & KX464846 \\
\hline & CBS 117.82 & KX464598 & KX464108 & KX464834 \\
\hline & UCD1061BC & EU012405 & EU012382 & EU012434 \\
\hline & UCD621Spa & GU294752 & DQ356357 & DQ356364 \\
\hline & IRB 15 & GU121848 & GU121890 & GU121835 \\
\hline & IRB3 & GU121850 & GU121878 & GU121823 \\
\hline & PPO-45237 & KX138559 & KX138556 & KX138560 \\
\hline & UCR1795 & JQ659274 & JQ659286 & JQ659298 \\
\hline & UCR1687 & JQ659273 & JQ659285 & JQ659297 \\
\hline \multirow{9}{*}{$\begin{array}{l}\text { Botryosphaeria } \\
\text { parva }\end{array}$} & CMW41361 & KP860694 & KP860850 & KP860772 \\
\hline & CMW38134 & KC769830 & KC769919 & KC769876 \\
\hline & MUCC673 & EU339520 & EU339553 & EU339483 \\
\hline & UCD578Spa & GU294748 & DQ356359 & DQ356366 \\
\hline & CMW1130 & AY236890 & AY236945 & AY236919 \\
\hline & CMW7885 & AY236889 & AY236944 & AY236918 \\
\hline & PD251 & GU251256 & GU251124 & GU251784 \\
\hline & CMW38724 & KF923277 & KF923244 & KF923265 \\
\hline & CMW37263 & KF454692 & KF432951 & KF454706 \\
\hline
\end{tabular}


Table 1 Continued.

\begin{tabular}{|c|c|c|c|c|}
\hline \multirow{2}{*}{ Species } & \multirow{2}{*}{ Strain number } & \multicolumn{3}{|c|}{ GenBank number } \\
\hline & & $E F-1 \alpha$ & ITS & $\beta$-tubulin \\
\hline & DL2611 & KC961032 & KC960892 & KC960987 \\
\hline & CDZ1-1s2 & HQ859955 & HQ859951 & HQ859953 \\
\hline & CMW14141 & EU821890 & EU821920 & EU821860 \\
\hline & IRN12 & GU121874 & GU121902 & GU121847 \\
\hline & PD39 & GU251276 & GU251144 & GU251804 \\
\hline & $5 \mathrm{~B} 602$ & KF779053 & KF778863 & KF778958 \\
\hline & CMW14082 & EU821877 & EU821907 & EU821847 \\
\hline & UCD577Spa & GU294747 & DQ356358 & DQ356365 \\
\hline & CMW9081 & AY236888 & AY236943 & AY236917 \\
\hline & MFLUCC11-0184 & JX646860 & JX646795 & JX646843 \\
\hline & CCF109 & KC507809 & KC507812 & KC507806 \\
\hline Botryosphaeria & MFLUCC14-0459 & N/A & KU848199 & N/A \\
\hline \multirow{2}{*}{ quercuum } & $96-186$ & N/A & AF243399 & N/A \\
\hline & CBS 177.89 & N/A & N/A & DQ026404 \\
\hline \multirow{17}{*}{$\begin{array}{l}\text { Botryosphaeria } \\
\text { rhodina }\end{array}$} & UCD1060BC & EU012396 & EU012376 & EU012428 \\
\hline & $7 \mathrm{E} 88$ & KC357297 & KC357279 & KC357288 \\
\hline & HD1332 & KU712503 & KU712502 & KU712504 \\
\hline & CMW9074 & AY236901 & AY236952 & AY236930 \\
\hline & MFLUCC14-0512 & KM409631 & KM396893 & KM510351 \\
\hline & 81.I & KC964552 & КC964548 & KC964551 \\
\hline & UCD2430TX & GU294713 & FJ790831 & GU294727 \\
\hline & SEFL28b & JN607115 & JN607092 & JN607139 \\
\hline & UCD1028BC & EU012394 & EU012374 & EU012426 \\
\hline & PD270 & GU251253 & GU251121 & GU251781 \\
\hline & CBS 287.47 & KX464639 & KX464145 & KX464914 \\
\hline & CMW41360 & KP860686 & KP860841 & KP860764 \\
\hline & FXPZ & KR232660 & KR232666 & KR232674 \\
\hline & MBAi184AG & KP721663 & KJ596529 & KP721701 \\
\hline & CMM3647 & KF226704 & KF234548 & KF254932 \\
\hline & SEAL9a & JN607113 & JN607090 & JN607137 \\
\hline & MFLUCC11-0508 & JX646864 & JX646799 & JX646847 \\
\hline \multirow{14}{*}{$\begin{array}{l}\text { Botryosphaeria } \\
\text { ribis }\end{array}$} & CMW7773 & DQ235142 & AY236936 & AY236907 \\
\hline & MUCC247 & EU339513 & EU301028 & EU339476 \\
\hline & SEGA5 & JN607121 & JN607098 & JN607145 \\
\hline & PD288 & GU251259 & GU251127 & GU251787 \\
\hline & H73-1 & HQ392755 & HQ392733 & HQ392754 \\
\hline & UCD2579MO & HQ288272 & HQ288230 & HQ288309 \\
\hline & CMW7772 & AY236877 & AY236935 & AY236906 \\
\hline & PD289 & GU251260 & GU251128 & GU251788 \\
\hline & SENC34a & JN607124 & JN607101 & JN607148 \\
\hline & MUCC125 & EU339514 & EU339525 & EU339477 \\
\hline & SENC29 & JN607123 & JN607100 & JN607147 \\
\hline & PD254 & GU251258 & GU251126 & GU251786 \\
\hline & SEGA8 & JN607122 & JN607099 & JN607146 \\
\hline & SEAL2 & JN607120 & JN607097 & JN607144 \\
\hline \multirow{6}{*}{$\begin{array}{l}\text { Botryosphaeria } \\
\text { sarmentorum }\end{array}$} & CBS 174.53 & KX464620 & KX464128 & KX464883 \\
\hline & PD78 & GU251301 & GU251169 & GU251829 \\
\hline & CBS 165.33 & AY573225 & AY573208 & KX464882 \\
\hline & CBS 120.41 & AY573224 & AY573207 & KX464880 \\
\hline & CMW39370 & KF575049 & KF575011 & KF575107 \\
\hline & CMW39364 & KF575048 & KF575010 & KF575106 \\
\hline
\end{tabular}


Table 1 Continued.

\begin{tabular}{lllll}
\hline \multirow{2}{*}{ Species } & \multirow{2}{*}{ Strain number } & \multicolumn{3}{c}{ GenBank number } \\
\cline { 3 - 5 } $\begin{array}{l}\text { Botryosphaeria } \\
\text { sinensia }\end{array}$ & cfcc82346 & KU221235 & ITS & $\boldsymbol{\beta}$-tubulin \\
Botryosphaeria & CGMCC 3.17723 & KU221233 & N/A & N/A \\
stevensii & UCR1670 & JQ659272 & JQ659284 & JQ659296 \\
& CBS 112553 & AY573219 & AY259093 & DQ458850 \\
& JL375 & DQ458871 & DQ458887 & DQ458852 \\
& UCROK1429 & JQ512121 & JQ411412 & JQ411443 \\
& UCD127-Oe & JX515786 & JX515745 & JX515674 \\
& CBS 230.30 & DQ458869 & DQ458886 & DQ458849 \\
& UCD1965SB & EU012413 & DQ233599 & DQ233620 \\
& CMW7060 & AY236904 & AY236955 & AY236933 \\
& CBS 112554 & DQ458870 & AY259095 & DQ458851 \\
& CMW7781 & N/A & AY972107 & AY972122 \\
& BEI36 & N/A & KT954166 & KT954167 \\
& UCD147-Oe & JX515787 & JX515746 & JX515675 \\
& UCROK1425 & JQ517318 & N/A & JQ411460 \\
& CBS 431.82 & N/A & KU198424 & KU198426 \\
\hline
\end{tabular}

\section{Materials for DNA barcoding verification}

Materials for DNA barcoding verification were obtained from B. stevensii isolated from apples imported from the United States and New Zealand, which had been morphologically identified. The $E F-1 \alpha$, ITS and $\beta$-tubulin genes were sequenced and submitted to the GenBank database. See details in Table 2.

Table 2 EF-1 $\alpha$, ITS and $\beta$-tubulin genes from Botryosphaeria stevensii isolates from apples.

\begin{tabular}{lllllll}
\hline \multirow{2}{*}{ No. } & \multirow{2}{*}{ Host } & \multirow{2}{*}{ Source } & $\begin{array}{l}\text { Collection } \\
\text { time }\end{array}$ & \multicolumn{4}{l}{ Gene sequence } \\
\cline { 5 - 7 } & & & EF -1 $\boldsymbol{\alpha}$ & ITS & $\boldsymbol{\beta}$-tubulin \\
\hline iso8438 & Apple & USA & 20160603 & KY465923 & KY465921 & KY644559 \\
iso2953 & Apple & New Zealand & 20160701 & KY465922 & KY465920 & KY644558 \\
iso50624 & Apple & New Zealand & 20160715 & KY465924 & KY465919 & KY644560 \\
\hline
\end{tabular}

\section{Isolation and culture}

Tissues showing signs of disease were collected from rotted fruit and used to inoculate potato dextrose agar (PDA) plates. After $3-5$ d of culture at $25^{\circ} \mathrm{C}$, the growth conditions of conidia were observed.

\section{DNA amplification and sequencing}

The mycelia were scraped from the PDA plates, ground to a powder in liquid nitrogen, and transferred to a $1.5 \mathrm{~mL}$ EP tube. The QIAGEN kit was used for DNA extraction. A $25 \mu \mathrm{L}$ reaction system was used for PCR amplification: $10 \times$ PCR buffer, $0.1 \mu \mathrm{M}$ of each primer, $0.25 \mathrm{mM}$ dNTPs, 1 U Taq DNA polymerase, and 10-100 ng template DNA. The primer sequences for $E F-1 \alpha$, ITS and $\beta$-tubulin are listed in Table 3. The reaction conditions were as follows: 35 cycles of $95{ }^{\circ} \mathrm{C}$ denaturation for $30 \mathrm{~s}$, annealing for $30 \mathrm{~s}$, and extension at $72{ }^{\circ} \mathrm{C}$ for $30 \mathrm{~s}$, followed by a $72{ }^{\circ} \mathrm{C}$ extension for $10 \mathrm{~min}$. The annealing temperatures used for EF-1 $\alpha$, ITS and $\beta$-tubulin amplification were $55^{\circ} \mathrm{C}, 57^{\circ} \mathrm{C}$ and $58{ }^{\circ} \mathrm{C}$, respectively. The amplification products were sent to a company for sequencing after purification. All samples were subjected to two-way sequencing. 


\section{Data processing}

SeqMan 5.0 software was adopted for sequence splicing and manual correction. After correction, the sequences were deposited in the GenBank database and subjected to a Blast search for homology comparison.

Table 3 Primer sequences used for PCR

\begin{tabular}{llll}
\hline $\begin{array}{l}\text { Gene } \\
\text { fragment }\end{array}$ & Primers & Sequence (5'--3') & Reference \\
\hline$E F-1 \alpha$ & EF1-728F & CATCGAGAAGTTCGAGAAGG & Carbone \& Kohn 1999 \\
& EF1-986R & TACTTGAAGGAACCCTTACC & White et al. 1990 \\
ITS & ITS4 & TCCTCCGCTTATTGATATGC & \\
& ITS5 & GGAAGTAAAAGTCGTAACAAGG & O'Donnell \& Cigelnik 1997 \\
$\beta$-tubulin & T1 & AACATGCGTGAGATTGTAAGT & $\begin{array}{l}\text { Glass \& Donaldson 1995 } \\
\end{array}$ \\
& Bt-2b & ACCCTCAGTGTAGTGACCCTTGGC & \\
\hline
\end{tabular}

\section{DNA barcoding analysis}

\section{Comparison of intraspecific and interspecific differences}

The intraspecific and interspecific genetic distances were determined by calculating a similarity matrix by means of inputting the selected genes into DNAstar software and using the Kimura-2-parameter distance (K2P) model implemented in the MEGA 5.0 software package. The frequency distribution was analyzed using Microsoft Excel.

\section{Statistical testing of differences in intraspecific and interspecific genetic distance}

SPSS 18.0 software was used to perform the Wilcoxon rank sum test to compare differences between gene sequences.

\section{Results}

\section{Screening of DNA barcoding genes of $B$. stevensii}

The distribution of intraspecific and interspecific genetic distances was determined by calculating each paired genetic distance of EF-1 $\alpha$, ITS and $\beta$-tubulin from B. stevensii and 11 closely related species, extracting intraspecific genetic distance data for all sequences in $B$. stevensii, and performing statistical analysis. The intraspecific and interspecific genetic distances of $E F-1 \alpha$ are shown in Fig. 1. There was no overlap between the intraspecific and interspecific genetic distance, which made it easy to distinguish the target species, B. stevensii, from other Botryosphaeria species that infect $M$. pumila. The intraspecific and interspecific genetic distances of the ITS fragment are shown in Fig. 2. There was an overlap between the intraspecific and interspecific genetic distance between 0 and 0.02 , which mainly consisted of the overlap between B. stevensii and closely related species B. obtusa and B. quercuum. The intraspecific and interspecific genetic distances of $\beta$-tubulin are shown in Fig. 3. There was an overlap in the intraspecific and interspecific genetic distance between 0 and 0.03 , which mainly consisted of the overlap between B. stevensii and B. australe, B. australis, B. iberica, B. obtusa, and B. parva.

\section{Intraspecific and interspecific genetic distance}

The minimum and average intraspecific and interspecific genetic distances for three genes

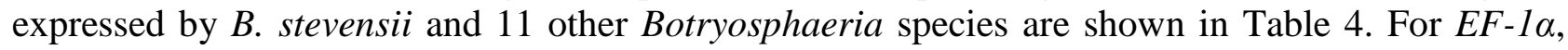
ITS and $\beta$-tubulin, the average interspecific genetic distance was far greater than the intraspecific genetic distance. The maximum and average intraspecific and interspecific genetic distances of $E F$ $1 \alpha$ were the greatest of the tested genes, followed by $\beta$-tubulin, whereas ITS had the smallest values. 


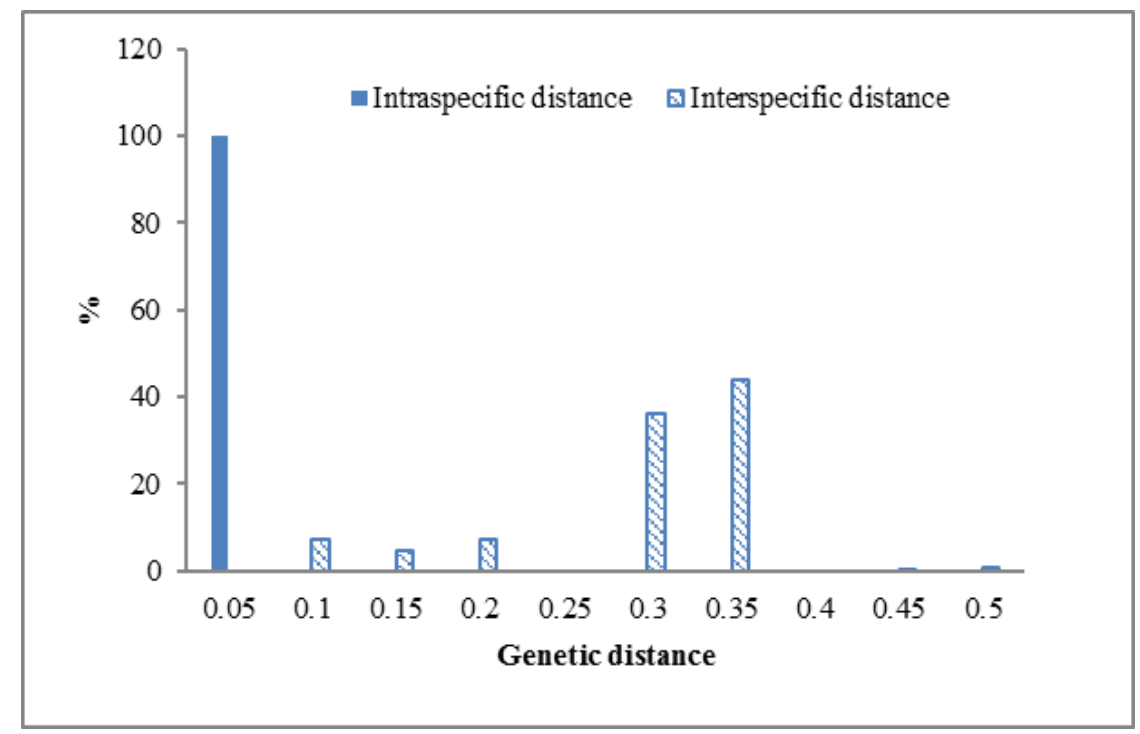

Fig. 1 - Intraspecific and interspecific genetic distance distribution based on the $E F-1 \alpha$ gene.

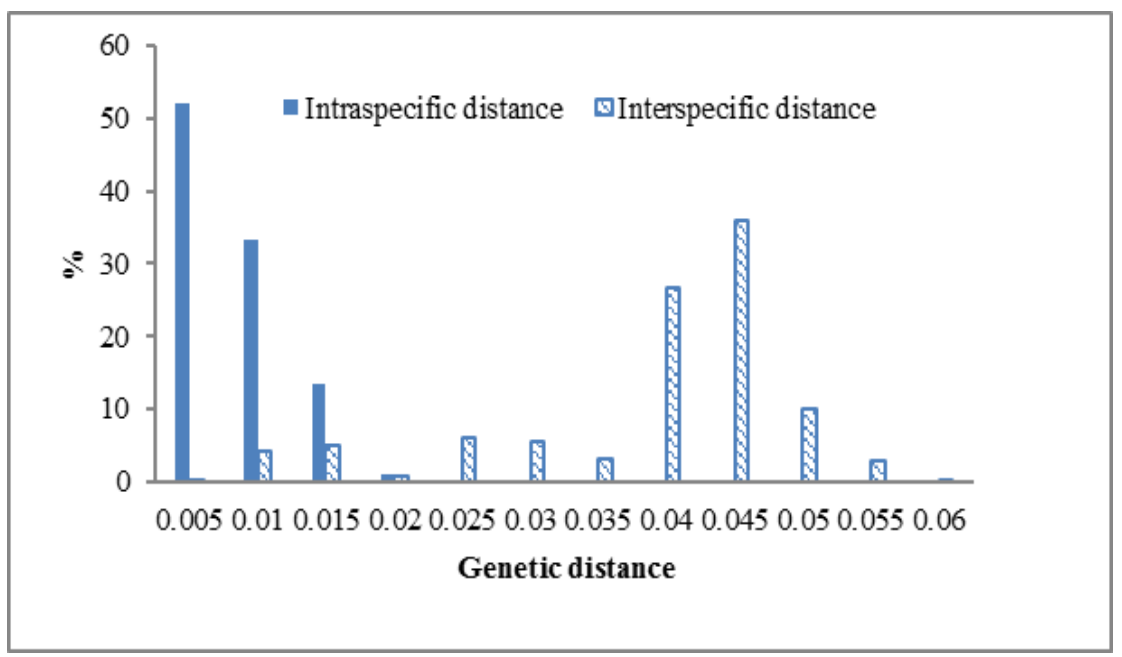

Fig. 2 - Intraspecific and interspecific genetic distance distribution based on the ITS fragment.

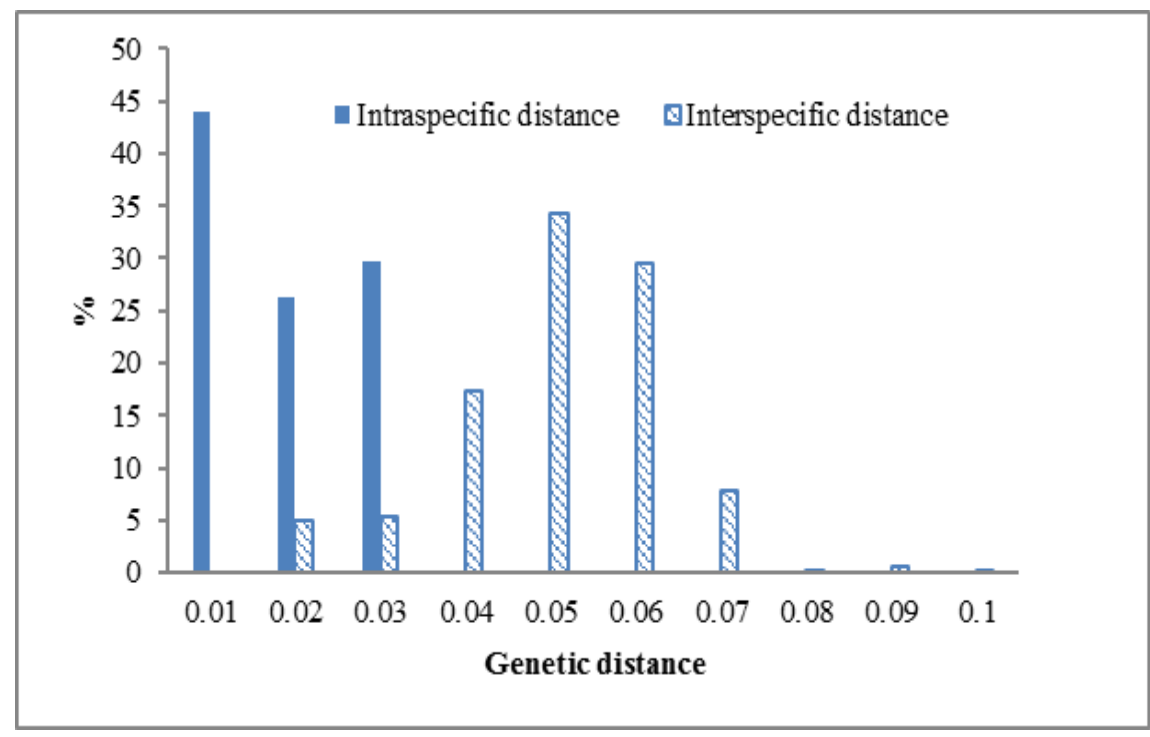

Fig. 3 - Intraspecific and interspecific genetic distance distribution based on the $\beta$-tubulin gene. 
Table 4 Intraspecific and interspecific genetic distance.

\begin{tabular}{lllllll}
\hline Gene & \multicolumn{3}{c}{ Intraspecific genetic distance } & \multicolumn{3}{c}{ Interspecific genetic distance } \\
\cline { 2 - 7 } & Maximum & Minimum & Average & Maximum & Minimum & Average \\
\hline$E F-1 \alpha$ & 0.037 & 0.000 & 0.017 & 0.467 & 0.091 & 0.267 \\
ITS & 0.019 & 0.000 & 0.005 & 0.057 & 0.002 & 0.037 \\
$\beta$-tubulin & 0.027 & 0.000 & 0.013 & 0.090 & 0.015 & 0.046 \\
\hline
\end{tabular}

\section{Wilcoxon rank sum test of sequence variation}

Wilcoxon rank sum tests were conducted on the intraspecific and interspecific genetic distances of $E F-1 \alpha$, ITS and $\beta$-tubulin to assess their degree of genetic variation. The test values of different gene fragments were compared (Tables 5,6) as the basis for selecting a DNA fragment for barcoding.

Table 5 Wilcoxon rank sum test of the intraspecific genetic distance of different sequences.

\begin{tabular}{|c|c|c|c|}
\hline Positive rank/ $\mathbf{W}^{+}$ & Negative rank/W'- & $\begin{array}{c}\text { Positive rank sum, } \\
\text { negative rank sum and } \\
\text { significant probability } P\end{array}$ & Result \\
\hline ITS & $E F-1 \alpha$ & $\mathrm{W}^{+}=1, \mathrm{~W}^{-}=51, \mathrm{P}=0.000$ & $E F-1 \alpha>$ ITS \\
\hline ITS & $\beta$-tubulin & $\mathrm{W}^{+}=6, \mathrm{~W}^{-}=79, \mathrm{P}=0.000$ & $\beta$-tubulin > ITS \\
\hline$E F-1 \alpha$ & $\beta$-tubulin & $\mathrm{W}^{+}=33, \mathrm{~W}^{-}=21, \mathrm{P}=0.004$ & $E F-1 \alpha>\beta$-tubulin \\
\hline
\end{tabular}

Table 6 Wilcoxon rank sum test of the interspecific genetic distance of different sequences.

\begin{tabular}{|c|c|c|c|}
\hline Positive rank/ $\mathbf{W}^{+}$ & Negative rank $/ \mathbf{W}^{-}$ & $\begin{array}{c}\text { Positive rank sum, } \\
\text { negative rank sum and } \\
\text { significant probability } P\end{array}$ & Result \\
\hline ITS & $E F-1 \alpha$ & $\mathrm{W}^{+}=0, \mathrm{~W}^{-}=1221, \mathrm{P}=0.000$ & $E F-1 \alpha>$ ITS \\
\hline ITS & $\beta$-tubulin & $\begin{array}{l}\mathrm{W}^{+}=293, \mathrm{~W}^{-}=1352 \\
\mathrm{P}=0.000\end{array}$ & $\beta$-tubulin > ITS \\
\hline$E F-1 \alpha$ & $\beta$-tubulin & $\mathrm{W}^{+}=1221, \mathrm{~W}^{-}=0, \mathrm{P}=0.000$ & EF-1 $\alpha>\beta$-tubulin \\
\hline
\end{tabular}

The analysis of interspecific and intraspecific genetic distances showed that the ranking of the effectiveness of the three tested genes for distinguishing intraspecific genetic distance was $E F-1 \alpha>$ $\beta$-tubulin > ITS $(\mathrm{p}<0.05)$. Taken together, the analyses of barcoding intervals and interspecific/intraspecific differences indicate that, among the tested gene fragments, the $E F-1 \alpha$ fragment is most suitable for DNA barcoding for rapid identification of $B$. stevensii.

\section{Detection of $B$. stevensii by DNA barcoding}

\section{PCR amplification and Blast search of the sequencing results}

The success rate of amplification and sequencing for $E F-1 \alpha$, ITS and $\beta$-tubulin sequences that had been isolated and morphologically verified in the laboratory was $100 \%$ (Table 2). The $E F-1 \alpha$, ITS and $\beta$-tubulin sequences were 271-274 bp, 487-567 bp and 512-591 bp in length, respectively. According to Blast searches of the NCBI database, the homology between the isolates and $B$. stevensii was $100 \%$ after proofreading and stitching of the sequencing results. Sequences were submitted to the GenBank database. The sequence numbers are shown in Table 2.

\section{Verification of the DNA barcoding fragments of the isolated strains}

The experiments described above show that $E F-1 \alpha$ is a suitable fragment for DNA barcoding of B. stevensii. During detection and identification of isolated strains iso50624, iso2953 and 
iso8438, the $E F-1 \alpha$ gene sequences of the isolated strains were arranged with those of $B$. stevensii and closely related species (Fig. 4). The $E F-1 \alpha$ gene sequences of the three isolated strains were identical with sequence AY573219, and there were significant differences between the sequences of the isolated strains and those of 11 closely related species. Therefore, it was determined that all three isolated strains were $B$. stevensii.

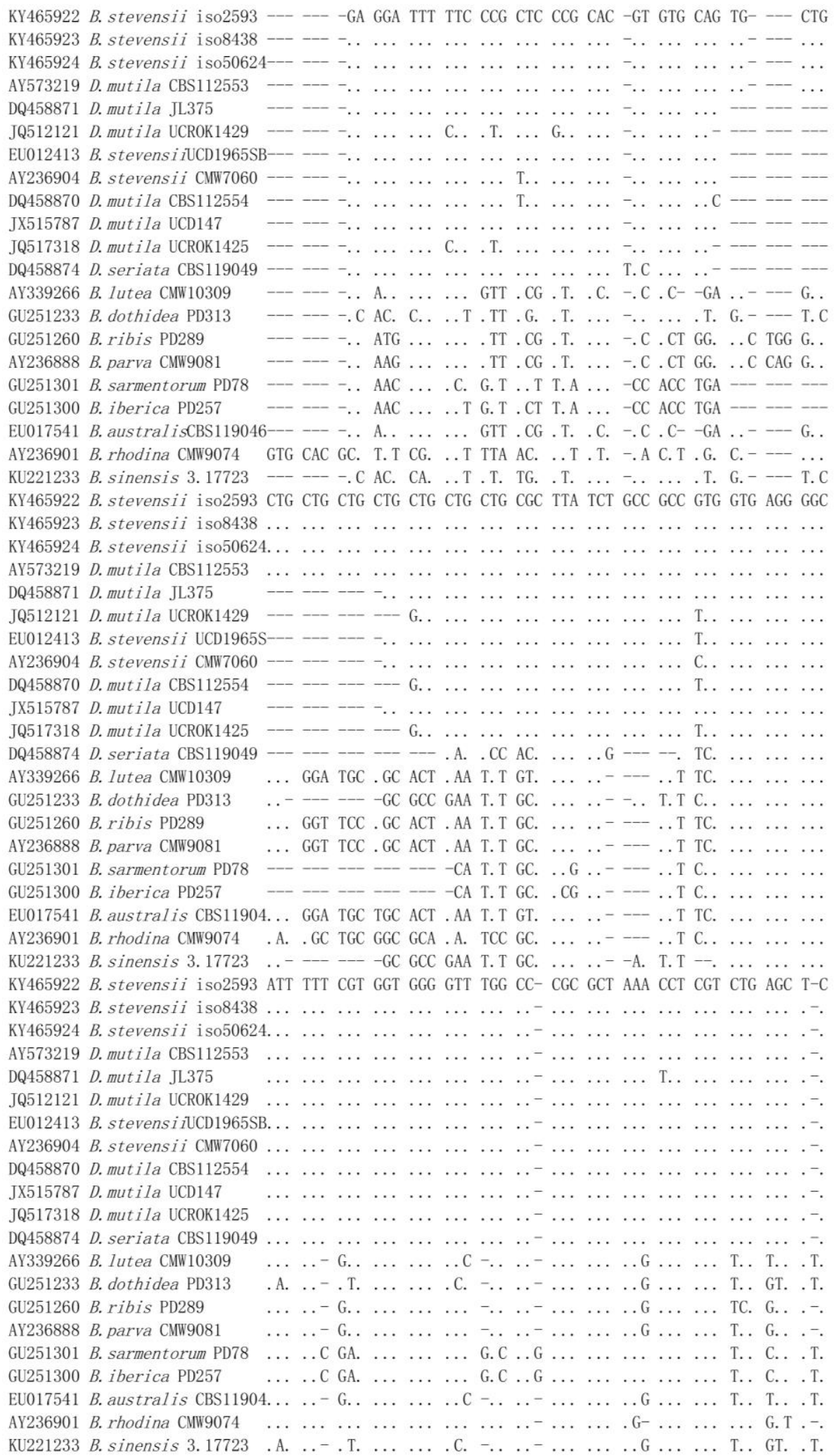


KY465922 B. stevensii iso2593 GGC AAA CTG GCC GCA CTT GGT TTT T-- --- GCG ACC GGT GTG AGG CCG KY465923 B. stevensii is $8438 \ldots \ldots \ldots \ldots \ldots \ldots$

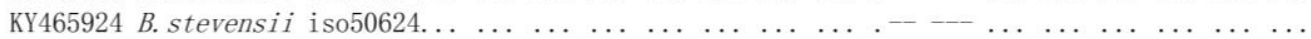

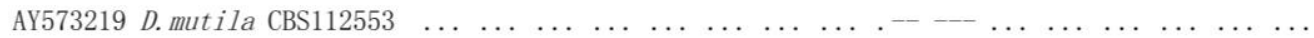

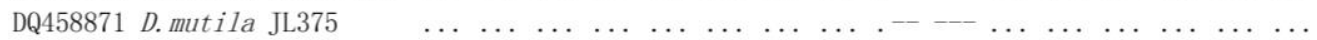

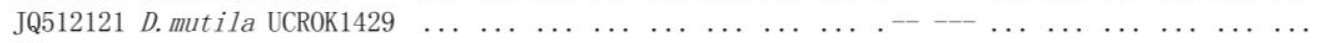

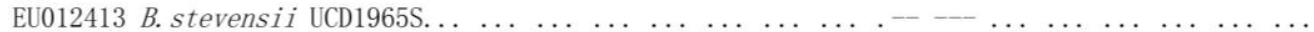
AY236904 B. stevensii CMW7060 $\ldots \ldots \ldots \ldots \ldots \ldots \ldots$

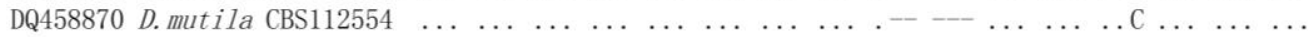

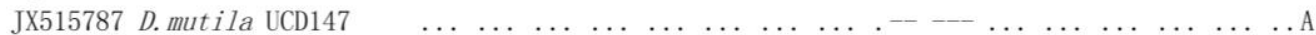

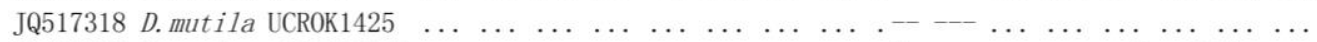

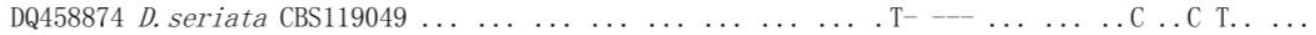
AY339266 B. Iutea CMW10309 …... А. С Т. . .. TC. ... ... . Т-

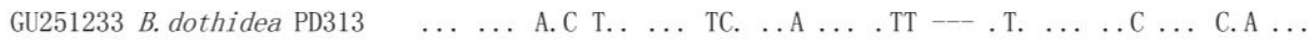

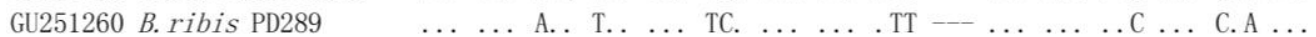

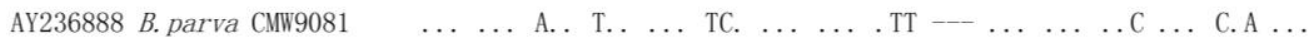

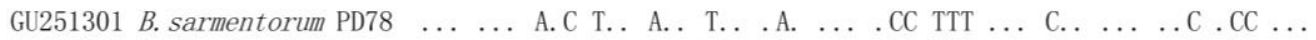

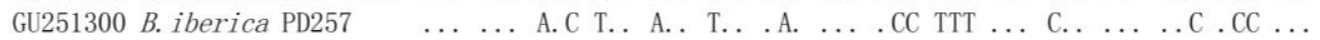

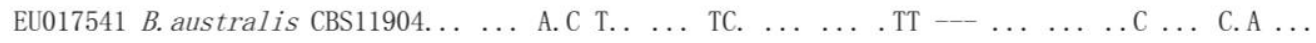

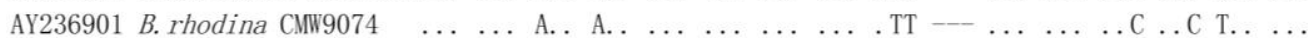

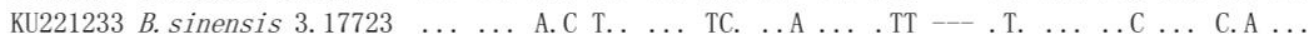
KY465922 B. stevensii iso2593 ATG CGC CCC CTC ACT AGC GAA AAA TGC CCC GAC CAC TCA TGT GCT CTC

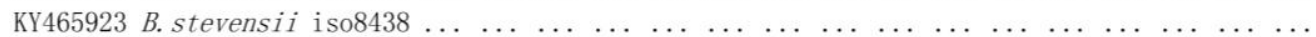

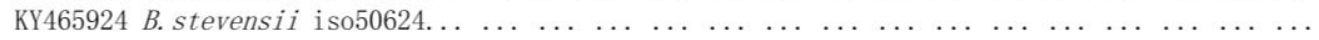

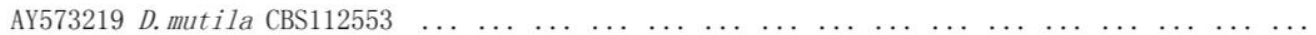

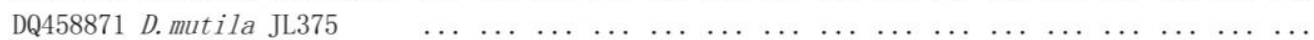

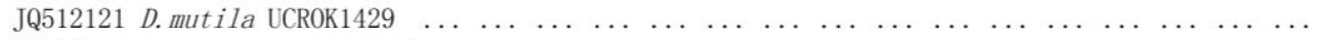

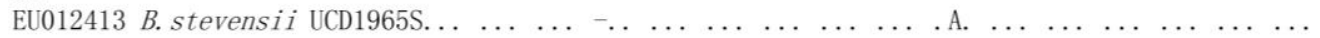

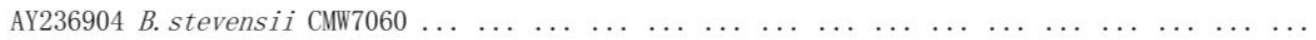

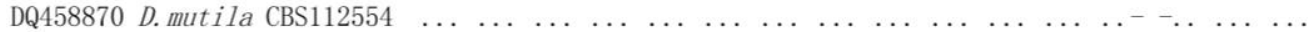
$\begin{array}{llllllllllllllllll}\text { JX515787 } & \text { D. mutila UCD147 } & \ldots & \ldots & \ldots & \ldots & \ldots & \ldots & \ldots & \ldots & \ldots & \ldots & \ldots & \ldots & \ldots & \ldots & \ldots & \ldots\end{array}$

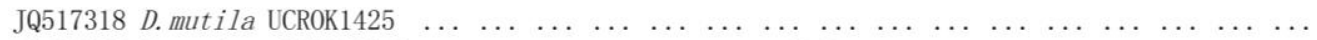

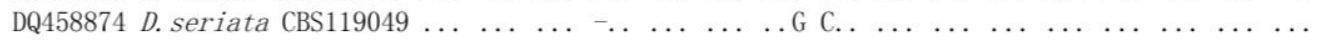
AY339266 B. Iutea CMW10309 .C. ... A....- CT. G. AGA . T. G.. GCC A.A .GU251233 B. dothidea PD313 .C. .. A A. A . C. -.. CA. C. CGC .-- T. . AG. ... ... C. . C. G TCT GU251260 B. ribis PD289 .A. ... G. . . AY236888 B. parva CMW9081 .A. ... G. . . - - C. G. . AGA ... G-- -CC A.G . AT GU251301 B. sarmentorum PD78 ... .C. .. G A.G -- C. . . CG TCC CT. A.. A. A A. . . T- . . A . . A ACT

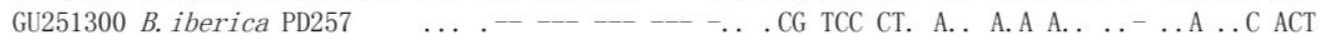
EU017541 B. australis CBS11904. A. ... G. . . - C. G. . AGA . T. G. . GCC ATA . AT

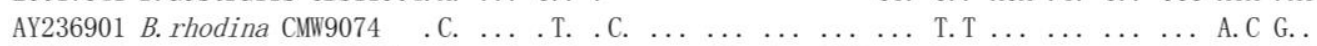
KU221233 B. sinensis 3.17723 .C. . . A A. A . C. -.. CA. C. . CGC .-- T. . AG. . . . . C. . T. G TCT KY465922 B. stevensii iso2593 GTA CGA CCA CAG GCT AAC GCG CGC CAC A

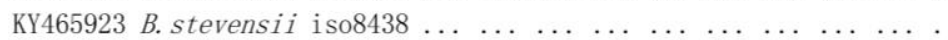

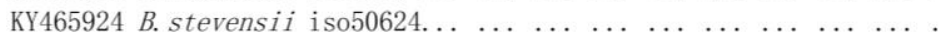

AY573219 D. mutila CBS112553 $\ldots \ldots \ldots \ldots \ldots \ldots$

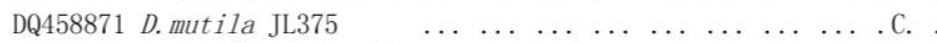

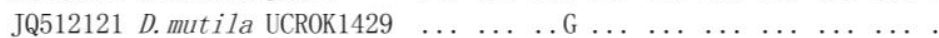

EU012413 B. stevensii UCD1965S. . . . . TT. $\ldots \ldots \ldots \ldots \ldots \ldots$

AY236904 B. stevensii CMW7060 $\ldots \ldots \ldots \ldots \ldots \ldots$

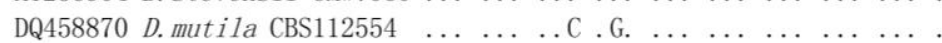

$\begin{array}{lllllllllll}\text { JX515787 D. mutila UCD147 } & \ldots & \ldots & \ldots & \ldots & \ldots & \ldots & \ldots & \ldots & \ldots\end{array}$

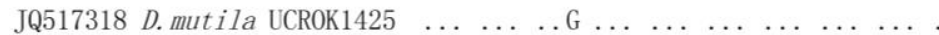

DQ458874 D. seriata CBS119049 $\ldots \ldots \ldots \ldots \ldots \ldots$

AY339266 B. lutea CMW10309 _.G ... T. G G. C ... ... . AC ..T .--

GU251233 B. dothidea PD313 ... . . . . . T. T ... . . CAC . . . . . .

GU251260 B. ribis PD289 _.G ...... G. . ...... . GC . AT .--

AY236888 B. parva CMW9081 _. G ... . . . G. C . . . . . AGC . AT .--

GU251301 B. sarmentorum PD78 CAG ... T. . GCT ... . . T ... C T. . T-- -

GU251300 B. iberica PD257 CAG ... T. . GCT ... . . T ... T T. T--

Eu017541 B. australis CBS11904.. G ... T. G G. C ... ... . AC ..T .--

AY236901 B. rhodina CMw9074 ... ... G. . A. . ... ........ . .. T

KU221233 B. sinensis 3. 17723 A. G ... ... T. T ... . . CAC . . . . .

Fig. 4 - Arrangement of Botryosphaeria stevensii and closely related species based on EF-1 $\alpha$. 


\section{Discussion}

Classification and identification of B. stevensii are mainly performed using morphological methods, in which the characteristics of colonies and asexual and sexual organs are assessed (Aldwinckle \& Jones 1990). However, we have found that it is difficult to induce B. stevensii to produce conidia and ascospores. Many types of medium have been assessed as methods of inducing sporulation, including PDA, 50\% PDA supplemented with alfalfa, PDA supplemented with pine needles, OA, OA supplemented with pine needles, water agar, water agar supplemented with pine needles, and apple medium (200 g apple steamed with water, $20 \mathrm{~g}$ water agar, $1000 \mathrm{~mL}$ water). $B$. stevensii spores were observed on water agar medium supplemented with pine needles after one month of culture. Because of the difficulty of inducing sporulation, identification of $B$. stevensii is time consuming, strenuous, and complicated. However, DNA barcoding based on the interspecific and intraspecific specificity of DNA fragments allows rapid and automatic identification of species and overcomes many limitations of traditional taxonomy methods, and this method has the potential to greatly simplify the process of identifying B. stevensii (Hebert et al. 2003, Hebert \& Gregory 2005).

As a new technique for species identification, DNA barcoding has enormous value in identification of fungi. Gao et al. (2013) employed DNA barcoding in the classification and identification of quarantined Phytophthora spp. DNA barcoding can be used to identify single spores, old samples, and other difficult samples, such as those containing little DNA, without requiring isolation and culture of pathogenic fungi. Each species has its own unique, verified DNA barcoding sequence. Although DNA barcoding in animals and plants has become an increasingly mature technology in recent years, the technique has been applied less frequently to plant pathogenic fungi. In addition, few studies have assessed DNA barcoding as a method of identifying genera or other higher taxonomic groups. The BOLD SYSTEMS database (http://boldsystems.org) is an authoritative database of DNA barcodes that can be used to identify a large number of species.

In this study, we utilized DNA barcoding to identify B. stevensii isolates from apples imported from North America and New Zealand. We selected 400 DNA barcoding sequences for three genes from 139 strains of 12 species in the genus Botryosphaeria for assessment of intraspecific and interspecific genetic variation, which revealed that $E F-1 \alpha$ is a suitable DNA barcoding fragment that should allow B. stevensii to be distinguished from closely related species capable of infecting $M$. pumila. Three B. stevensii strains isolated from imported apples from the United States and New Zealand were identified to verify the accuracy of the DNA barcoding method used in this study. Sequence information for $E F-1 \alpha$ was obtained, and an $E F$ - $1 \alpha$-based DNA barcode was established for $B$. stevensii. In addition, conserved and mutated $E F-1 \alpha$ sites in $B$. stevensii and closely related species were identified. These findings provide a basis for specific primer and probe design for $E F-1 \alpha$ and establishment of specific detection methods and corresponding technical standards. With a database of the biological information of target species established, and the capability to identify pathogenic fungi using a small amount of mycelium, DNA barcoding will sharply reduce the time required for detection and identification of $B$. stevensii and improve the accuracy of identification. The use of DNA barcoding to determine which fruit should be quarantined could facilitate efficient operation of customs offices at frontier ports.

\section{References}

Aldwinckle HS, Jones AL. 1990 - Compendium of apple and pear diseases. APS Press.

Carbone I, Kohn LM. 1999 - A method for designing primer sets for speciation studies in filamentous ascomycetes. Mycologia 91, 553-556.

Gao RF, Zhang GM. 2013 - Potential of DNA barcoding for detecting quarantine fungi. Phytopathology 103, 1103-1107.

Glass NL, Donaldson GC. 1995 - Development of primer sets designed for use with the PCR to amplify conserved genes from filamentous ascomycetes. Applied and Environmental Microbiology 61, 1323-1330. 
Hebert PDN, Gregory TR. 2005 - The promise of DNA barcoding for taxonomy. Systematic Biology 54, 852-859.

Hebert PDN, Cywinska A, Ball SL. 2003 - Biological identifications through DNA barcodes. Proceedings of the Royal Society of London B: Biological Sciences 270, 313-321.

Farr DF, Rossman AY. 2018 - Fungal Databases, U.S. National Fungus Collections, ARS, USDA. Retrieved October 17, from https://nt.ars-grin.gov/fungaldatabases/

Miller SE. 2007 - DNA barcoding and the renaissance of taxonomy. Proceedings of the National Academy of Sciences of the United States of America 104, 4775-4776.

O’Donnell K, Cigelnik E. 1997 - Two divergent intragenomic rDNA ITS2 types within a monophyletic lineage of the fungus Fusarium are nonorthologous. Molecular Phylogenetics and Evolution 7, 103-116.

Shoemaker RA. 1964 - Conidial states of some Botryosphaeria species on Vitis and Quercus. Canadian Journal of Botany 42, 1297-1301.

Urbeztorres JR, Leavitt GM, Voegel T, Gubler W. 2006 - Identification and distribution of Botryosphaeria spp. associated with grapevine cankers in California. Plant Disease 90, 1490-1503.

Wang WH, Zhang QE, Huang Y, Yan J, Hua L. 2014 - Detection and identification of Botryosphaeria stevensii Shoemaker. Standards Press of China. SN/T 3750-2013.

White TJ, Bruns TD, Lee SB, Taylor JW. 1990 - Amplification and direct sequencing of fungal ribosomal RNA genes for phylogenetics. PCR protocols: a guide to methods and applications $18,315-322$.

Whitelaw-Weckert MA, Sergeeva V, Priest MJ. 2006 - Botryosphaeria stevensii infection of Pinot Noir grapevines by soil-root transmission. Australasian Plant Pathology 35, 369-371. 